\title{
Motor Pattern Selection via Inhibition of Parallel Pathways
}

\author{
Dawn M. Blitz and Michael P. Nusbaum \\ Department of Neuroscience, University of Pennsylvania School of Medicine, Philadelphia, Pennsylvania 19104
}

Motor pattern selection from a multifunctional neural network often results from direct synaptic and modulatory actions of different projection neurons onto neural network components. Less well documented is the presence and function of interactions among distinct projection neurons innervating the same network. In the stomatogastric nervous system of the crab Cancer borealis, several distinct projection neurons that influence the pyloric and gastric mill rhythms have been studied. These rhythms are generated by overlapping subsets of identified neurons in the stomatogastric ganglion (STG). One of these identified projection neurons is the modulatory proctolin neuron (MPN). We showed previously that MPN stimulation excites the pyloric rhythm by its excitatory actions on STG neurons. In contrast to its excitatory actions on the pyloric rhythm, we have now found that MPN inhibits the gastric mill rhythm. This inhibition does not occur within the STG, but instead results from MPN-mediated inhibition of two previously identified projection neurons within the commissural ganglia. These projection neurons innervate the STG and, via their actions on STG neurons, they elicit the gastric mill rhythm as well as modify the pyloric rhythm in a manner distinct from MPN. By inhibiting these projection neurons, MPN removes excitatory drive to gastric mill neurons and elicits an MPNspecific pyloric rhythm. Motor pattern selection by MPN therefore results from both a direct modulation of STG network activity and an inhibition of competing pathways.

Key words: stomatogastric nervous system; crustacea; projection neurons; neuromodulation; Cancer borealis
Neuromodulatory inputs enable rhythmically active neural networks to produce multiple distinct motor patterns (HarrisWarrick and Marder, 1991; Soffe, 1993; Dickinson, 1995; Katz, 1995; Kiehn and Kjærulff, 1996; Marder and Calabrese, 1996). These networks are often influenced by sets of distinct modulatory neurons (Weeks and Kristan, 1978; Brodfuehrer and Friesen, 1986; Nusbaum and Kristan, 1986; Rosen et al., 1991; Rossignol and Dubuc, 1994; Grillner et al., 1995; Marder et al., 1995; Thorogood and Brodfuehrer, 1995). However, little information is available regarding whether distinct inputs to any single network act exclusively as independent parallel pathways or whether they also interact with one another (Brodfuehrer and Burns, 1995; Faumont et al., 1996).

This issue can be studied effectively in the stomatogastric nervous system (STNS) of decapod crustacea (Harris-Warrick et al., 1992a; Marder and Weimann, 1992). The STNS consists of the stomatogastric ganglion (STG), the esophageal ganglion (OG), and the paired commissural ganglia (CoGs). In the crab Cancer borealis, overlapping subsets of STG neurons generate the gastric mill and pyloric rhythms (Weimann et al., 1991; Weimann and Marder, 1994). These rhythms control chewing and the movement of chewed food from the foregut to the midgut, respectively (Johnson and Hooper, 1992). Different versions of these two rhythms are elicited by superfusion of different neuromodulators (Harris-Warrick et al., 1992b; Marder and Weimann, 1992; Weimann et al., 1993; Skiebe and Schneider, 1994; Blitz et al., $1995)$ and by activation of different sensory and projection neu-

Received March 14, 1997; revised April 14, 1997; accepted April 16, 1997.

This work was supported by National Science Foundation Grant IBN94-96264, National Institute of Neurological Disorders and Stroke Grant NS-29436, National Institute of Mental Health Training Grant MH-17168, and the Human Frontiers Science Program.

Correspondence should be addressed to Dr. Michael P. Nusbaum, Department of Neuroscience, 215 Stemmler Hall, University of Pennsylvania School of Medicine, Philadelphia, PA 19104-6074.

Copyright (C) 1997 Society for Neuroscience $\quad 0270-6474 / 97 / 174965-11 \$ 05.00 / 0$ rons (Nusbaum and Marder, 1989a,b; Katz and Harris-Warrick, 1991; Coleman and Nusbaum, 1994; Norris et al., 1994a, 1996; Blitz and Nusbaum, 1996; Bartos and Nusbaum, 1997).

One identified projection neuron in the crab STNS is the modulatory proctolin neuron (MPN) (Nusbaum and Marder, 1989a,b). MPN projects from the OG to the STG and both CoGs. The modulatory effects of MPN activity on pyloric circuit neurons in the STG result in a pyloric rhythm that is comparable to that resulting from superfusion of the neuropeptide proctolin. Nusbaum and Marder (1989a,b) did not study the MPN influence on the gastric mill rhythm, because all CoG inputs were eliminated in their experiments, and in C. borealis, this rhythm depends on input from CoG projection neurons (Coleman and Nusbaum, 1994; Norris et al., 1994a).

Here, we show that MPN stimulation inhibits the gastric mill rhythm. However, MPN does not directly inhibit any STG neurons. Instead, MPN inhibits two identified $\mathrm{CoG}$ projection neurons, the activity of which elicits gastric mill rhythms. These CoG neurons are modulatory commissural neuron 1 (MCN1) (Coleman and Nusbaum, 1994; Coleman et al., 1995) and commissural projection neuron 2 (CPN2) (Norris et al., 1994a). MPN activity also enhances or evokes pyloric-timed activity in many gastric mill neurons via its modulatory actions in the STG. Thus, via its combined excitatory actions on STG network neurons and its inhibitory actions on CoG projection neurons, MPN activity biases the STG network to produce a specific pyloric rhythm in the absence of the gastric mill rhythm. Some of this work has appeared previously in abstract form (Blitz and Nusbaum, 1994).

\section{MATERIALS AND METHODS}

Animals. Crabs, Cancer borealis, were obtained from commercial suppliers (Boston, MA) and from the Marine Biological Laboratory (Woods Hole, MA). Crabs were maintained in aerated artificial seawater at $10-12^{\circ} \mathrm{C}$. Immediately before dissection, crabs were cold anesthetized by packing in ice for 20-40 min. The foregut, including the STNS, was removed and pinned in a silicone elastomer (SYLGARD 170, Dow 


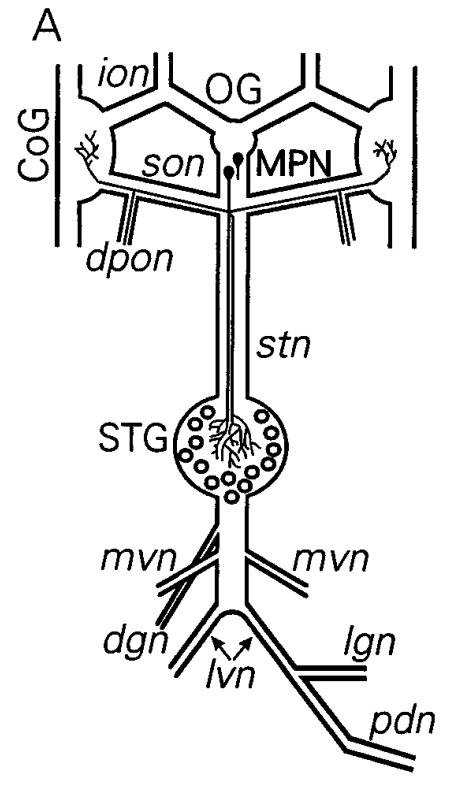

$\mathrm{B}$

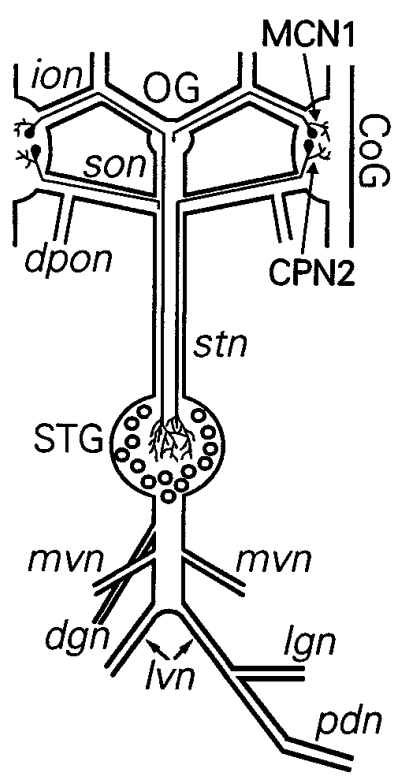

Figure 1. Schematics of the STNS, including somata location and axonal pathway of the identified projection neurons MPN, MCN1, and CPN2. A, There is a pair of MPN somata located either in the OG or in the nerve posterior to this ganglion. Each MPN projects an axon through each superior esophageal nerve (son) to the $\mathrm{CoG}$ and through the stomatogastric nerve $(s t n)$ to the STG. It also projects an axonal branch from each superior esophageal nerve through the peripheral nerve dorsal posterior esophageal nerve (dpon). For clarity, the complete projection of only one MPN is shown. $B$, There is a single MCN1 and CPN2 in each CoG. Each MCN1 projects through the inferior esophageal nerve (ion) and stomatogastric nerve to the STG. Each CPN2 projects through the superior esophageal nerve and stomatogastric nerve to the STG. For clarity, the complete projection of only one MCN1 and one CPN2 is shown. CoG, Commissural ganglion; $O G$, esophageal ganglion; $d g n$, dorsal gastric nerve; lgn, lateral gastric nerve; lvn, lateral ventricular nerve; $m v n$, medial ventricular nerve; $p d n$, pyloric dilator nerve; $C P N 2$, commissural projection neuron $2 ; M C N 1$, modulatory commissural neuron $1 ; M P N$, modulatory proctolin neuron. Anterior is toward the top of the figure and posterior is toward the bottom.

Corning, Midlands, MI)-lined bowl filled with chilled $\left(\sim 4^{\circ} \mathrm{C}\right)$ physiological saline. The STNS was then dissected free from the foregut. Data were obtained from 95 male crabs.

Solutions. C. borealis physiological saline had the following composition (in mM): $\mathrm{NaCl} 440, \mathrm{MgCl}_{2} 26, \mathrm{CaCl}_{2} 13, \mathrm{KCl} 11$, Trisma base 10 , maleic acid 5, pH 7.4-7.6. Low $\mathrm{Ca}^{2+}$ saline had the following composition (in mM): $\mathrm{NaCl} 440, \mathrm{MgCl}_{2} 26, \mathrm{CaCl}_{2} 1.3, \mathrm{KCl} 11, \mathrm{MnCl}_{2} 11.7$, Trisma base 10, maleic acid 5, $\mathrm{pH}$ 7.4-7.6. Saline of this composition blocks transmitter release in the crab STNS (Coleman, 1995; Coleman et al., 1995). $F_{1}$ peptide (TNRNFLRFamide) was obtained from Peninsula (Belmont, CA). Oxotremorine was obtained from Sigma (St. Louis, MO).

Electrophysiology. Electrophysiological experiments were performed using standard techniques for this system (Selverston and Moulins, 1987; Bartos and Nusbaum, 1997). The isolated STNS (Fig. 1) was pinned down in a silicone elastomer- (SYLGARD 184, Dow Corning) lined Petri dish. In a few experiments $(n=4)$, a semi-intact preparation was used in which some STG motor nerves innervated their target pyloric and/or gastric mill muscles. For these preparations, the posterior stomach wall and associated muscles along with the STNS were pinned down in a SYLGARDlined Petri dish. All preparations were superfused continuously at 7-12 $\mathrm{ml} / \mathrm{min}$ with crab physiological saline $\left(10^{\circ}-13^{\circ} \mathrm{C}\right)$. Intracellular and extracellular recordings were performed as reported previously (Bartos and Nusbaum, 1997). Intracellular current injection was performed using Axoclamp 2 amplifiers (Axon Instruments, Foster City, CA) in singleelectrode discontinuous current clamp mode. Sample rates during discontinuous current clamp were $\sim 3 \mathrm{KHz}$. Data were collected on chart recorder (Astro-Med MT-95000) and videotape (Vetter Instruments, Rebersburg, PA).

In some experiments, the anterior portion of the STNS (CoGs and OG) was superfused separately from the STG so that it could be superfused selectively with low $\mathrm{Ca}^{2+}$ saline via a switching manifold. To this end, the two compartments were separated by building a petroleum jelly wall across the recording dish. Gastric mill rhythms were spontaneous or elicited in some preparations by superfusing a combination of the neuropeptide $\mathrm{F}_{1}\left(10^{-7} \mathrm{M}\right)$ and the muscarinic agonist oxotremorine $\left(10^{-7}-10^{-5} \mathrm{M}\right)$ to the entire preparation (Weimann et al., 1993). All results were the same for spontaneous and transmitter-elicited gastric mill rhythms. Therefore, these data were pooled. In one series of control experiments, gastric mill rhythms were elicited by selective activation of MCN1 via extracellular stimulation of the inferior esophageal nerve (ion15-20 Hz) (Coleman, 1995; Coleman et al., 1995). The ion was stimulated using a Grass S88 stimulator and Grass SIU5 stimulus isolation unit (Astro-Med/Grass Instruments, Quincy, MA). Throughout the paper, the phrases pyloric-timed and gastric mill-timed indicate activity that is time-locked to the pyloric- or gastric mill rhythm, respectively.

Individual STG neurons were identified electrophysiologically by documenting the activity pattern and axon projection pattern of each neuron as well as its synaptic interactions with other identified neurons (Weimann et al., 1991; Coleman and Nusbaum, 1994; Norris et al., 1994a, 1996; Coleman et al., 1995; Bartos and Nusbaum, 1997). The mean number of spikes per pyloric-timed burst in individual STG neurons was determined by calculating the mean number of spikes per burst from 10 consecutive cycles before and during MPN stimulation.

Figures were made by scanning data with an HP ScanJetIIC, using DeskScan II (version 2.00a) software. Final figures were produced using CorelDraw (Version 3.0 for Windows). Paired Student's $t$ test, performed with SigmaPlot for Windows (Version 1.02), was used to determine statistical significance. Data are expressed as mean \pm SD.

\section{RESULTS \\ MPN inhibits the gastric mill rhythm}

The gastric mill rhythm produces alternating protraction and retraction movements of the paired lateral teeth and the single medial tooth in the gastric mill region of the crustacean stomach (Heinzel et al., 1993). In the isolated crab STNS, the gastric mill rhythm has a characteristic period that ranges between 8 and $15 \mathrm{sec}$ (Norris et al., 1994a). The crab STG produces several forms of the gastric mill rhythm, both in vitro (Coleman et al., 1993; Weimann et al., 1993; Coleman and Nusbaum, 1994; Norris et al., 1994a) and in vivo (Powers, 1973; Heinzel et al., 1993).

Examples of the two most common versions of the gastric mill rhythm recorded in vitro in C. borealis are shown in Figure 2. One standard characteristic of these two gastric mill rhythms is the alternating bursting of the lateral gastric ( $L G$, lateral teeth protractor) and dorsal gastric ( $D G$, medial tooth retractor) motor neurons. The gastric mill rhythm shown in Figure $2 A$ is also characterized by inhibition of the ventricular dilator $(V D)$ neuron ( $m v n$ ) during each LG burst and weak or absent gastric mill (GM) neuron (dgn, smallest unit) activity. This gastric mill rhythm is elicited by selective activation of the $\mathrm{CoG}$ projection neuron MCN1 (Fig. 1B) (Nusbaum et al., 1992; Coleman and Nusbaum, 1994; Coleman et al., 1995). Furthermore, when this rhythm is elicited by application of neuromodulators to the STNS or results from spontaneous activity, MCN1 activity is always evident in extracellular recordings of the ion (Coleman and Nusbaum, 1994). Finally, suppressing MCN1 activity eliminates this rhythm (Coleman, 1995). Thus, in this paper, we have designated this version of the gastric mill rhythm the MCN1-elicited gastric mill rhythm.

The gastric mill rhythm shown in Figure $2 B$ has several features that distinguish it from the MCN1-elicited rhythm. For example, the cycle period is generally longer, and each LG burst is more intense (Norris et al., 1994a). Additionally, overlapping with each LG burst is intense GM neuron (dgn) bursting and inhibition of both the inferior cardiac (IC) and VD neurons (mvn). Simulta- 

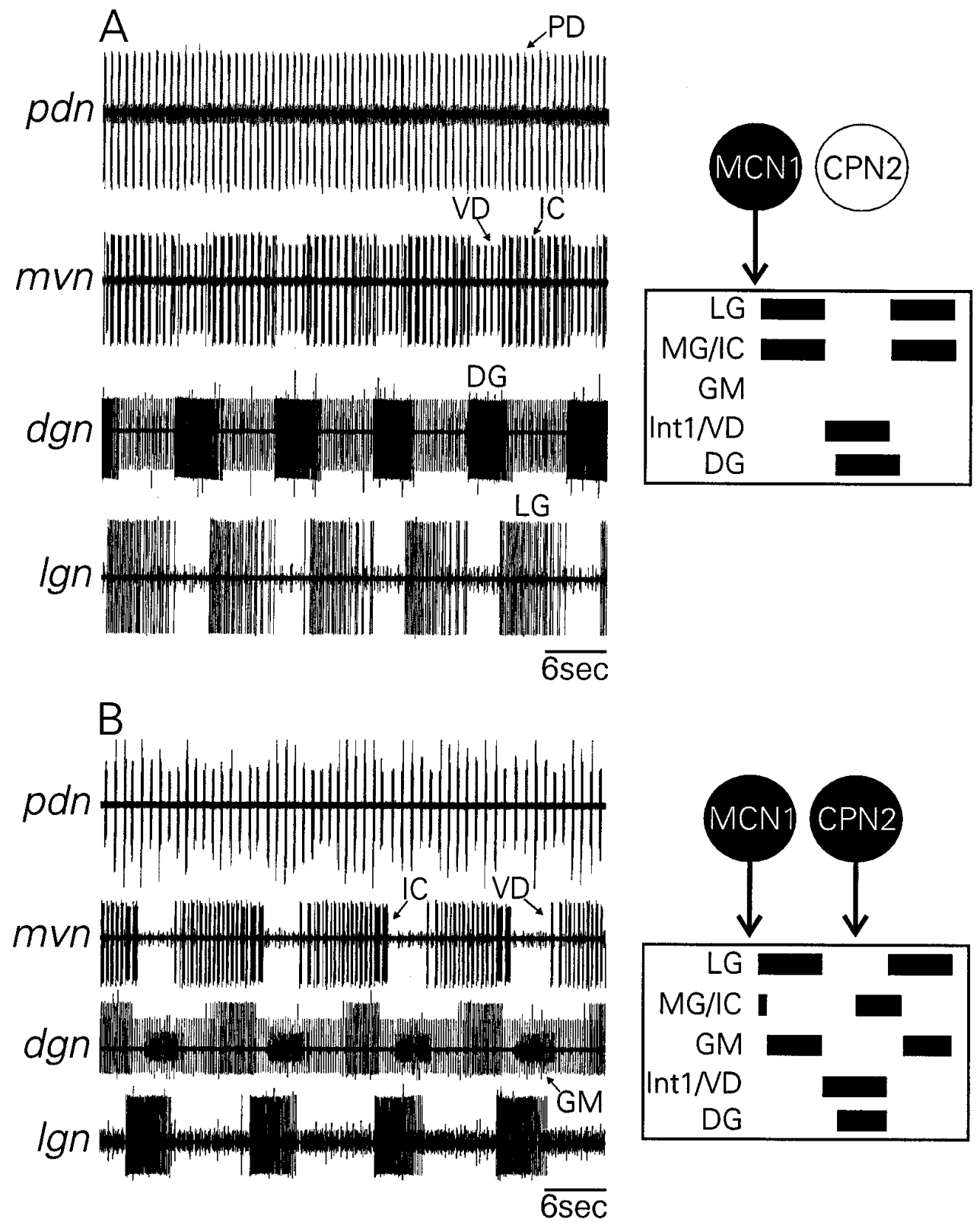

neous activation of two CoG projection neurons, MCN1 and CPN2 (Fig. 1B), elicits this rhythm (Norris et al., 1994a) (see below). Thus, this rhythm has been designated the MCN1/CPN2elicited gastric mill rhythm.

Intracellular stimulation of MPN consistently inhibited these two gastric mill rhythms. As is evident in Figure $3 A$, MPN stimulation inhibited ongoing MCN1-elicited gastric mill rhythms ( $n=13$ preparations). Accordingly, during these MPN stimulations, the gastric mill-timed bursts in the LG and DG neurons were suppressed. Note that the MPN stimulation also enhanced the ongoing pyloric rhythm (Fig. $3 A, m v n$ ). This excitation of the pyloric rhythm results from MPN excitation of the pyloric neurons in the STG (Nusbaum and Marder, 1989b). The suppression of the gastric mill rhythm often persisted for $>10 \mathrm{sec}$ after MPN stimulation was terminated, after which there was a gradual buildup in rhythmic activity before the rhythm returned to prestimulus levels.

Similarly, intracellular stimulation of MPN reversibly inhibited
Figure 2. Examples of gastric mill rhythms elicited by MCN1 alone and by conjoint activity in MCN1 and CPN2. $A$, Left, Extracellular recordings of STG motor nerves during an MCN1-elicited gastric mill rhythm (mvn, dgn, lgn) and pyloric rhythm $(p d n)$. This gastric mill rhythm is characterized by rhythmic alternating bursting in the LG $(\lg n)$ and DG (dgn) neurons. The VD neuron (smaller unit in the $m v n$ ) is silent during each LG burst, and IC (larger unit in the $m v n)$ is silent during each DG burst. Right, Schematic of the time of activity of STG neurons during an MCN1-elicited gastric mill rhythm. This gastric mill rhythm was elicited by selective stimulation of MCN1 (see also Coleman and Nusbaum, 1994; Coleman et al., 1995). B, Left, Extracellular recordings monitoring the pyloric and gastric mill rhythms during coactivation of $\mathrm{MCN} 1$ and $\mathrm{CPN} 2$. This gastric mill rhythm differs in several ways from the rhythm elicited by selective activation of MCN1. The cycle period is longer, both IC and VD (mvn) are completely inhibited during each LG burst, and the GM neurons (smallest unit in $d g n$ ) are strongly activated during each LG burst (see also Norris et al., 1994a). Right, Schematic of the time of activity of STG neurons during an MCN1/CPN2elicited gastric mill rhythm. In this recording, MCN1 and CPN2 were activated by bath application of $10^{-5} \mathrm{M}$ oxotremorine to the entire preparation. The tonically active unit in the $d g n$ in these and all subsequent dgn recordings is the anterior gastric receptor sensory neuron. Dark cell bodies represent active neurons; light cell bodies represent inactive neurons.
MCN1/CPN2-elicited gastric mill rhythms ( $n=10$ preparations). As was the case for MCN1-elicited gastric mill rhythms, MPN stimulation caused a long-lasting elimination of all gastric milltimed activity and enhanced the ongoing pyloric rhythm (Fig. $3 B$ ). These gastric mill rhythms typically resumed within $20 \mathrm{sec}$ after MPN stimulation was terminated.

MPN projects axons to the CoGs and STG (Nusbaum and Marder, 1989a) (Fig. 1A). Therefore, its inhibition of the gastric mill rhythm could have occurred in the STG via inhibition of gastric mill circuit neurons and/or the STG terminals of MCN1 and CPN2. The STG terminals of projection neurons are known to receive synaptic input from STG circuit neurons (Nusbaum et al., 1992; Coleman and Nusbaum, 1994). Alternatively, the MPN inhibition of the gastric mill rhythm could have occurred via an inhibition of MCN1 and CPN2 in the CoGs. We examined the influence of MPN activity in the STG and CoGs and found that MPN influenced the activity of gastric mill circuit neurons via its actions in both locations. 

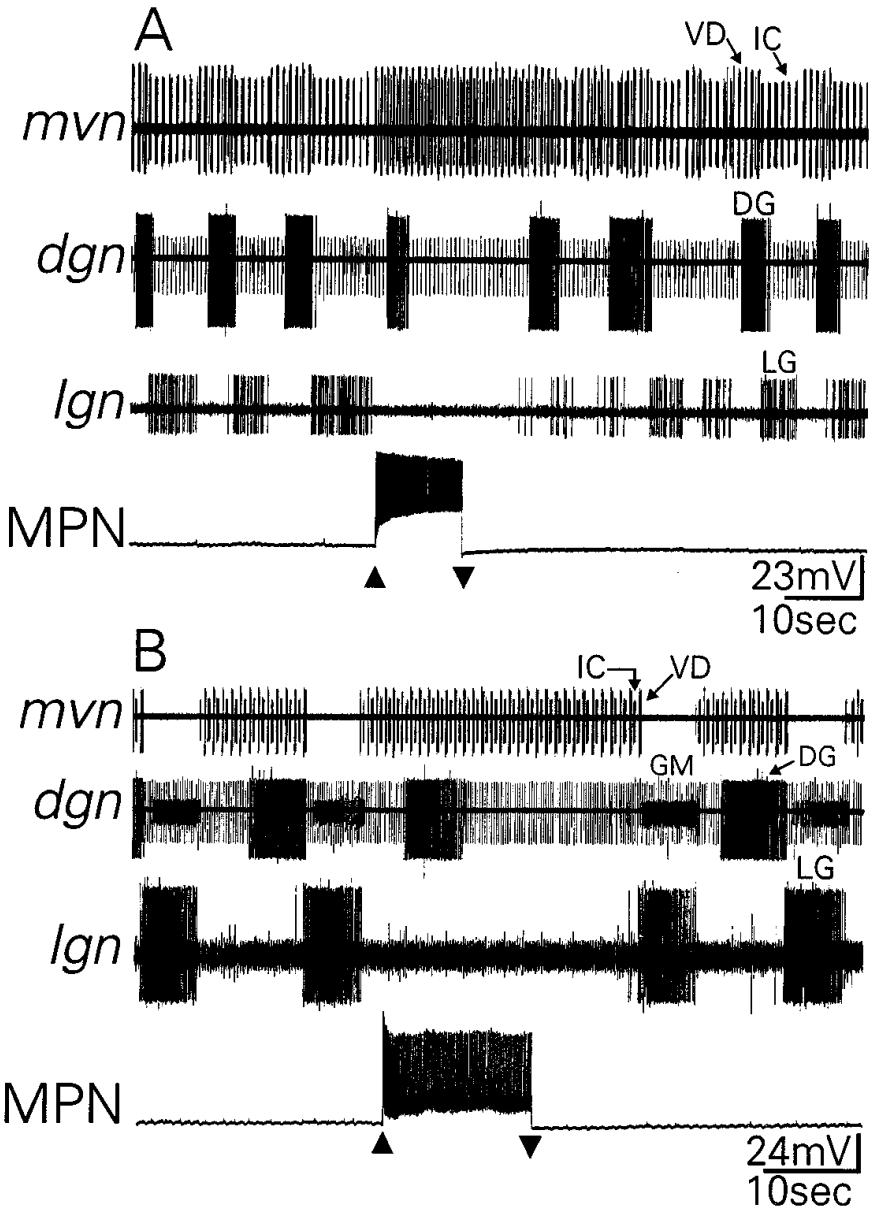

Figure 3. MPN activity inhibits the gastric mill rhythm. A, An ongoing MCN1-elicited gastric mill rhythm is suppressed by intracellular stimulation of MPN (firing frequency, $13 \mathrm{~Hz}$ ). This resulted in termination of activity in the LG and DG neurons and the elimination of gastric milltimed inhibition of the VD and IC neurons. The gastric mill rhythm resumed $10 \mathrm{sec}$ after the end of the MPN stimulation. B, An MCN1/ CPN2-elicited gastric mill rhythm was evoked by bath application of $10^{-6}$ $\mathrm{M}$ oxotremorine and $10^{-7} \mathrm{M} \mathrm{F}_{1}$ peptide to the entire preparation. This rhythm was suppressed by MPN stimulation (firing frequency, $11 \mathrm{~Hz}$ ), resulting in immediate termination of activity in the LG and GM neurons and the elimination of the gastric mill-timed inhibition in the $m v n$. Shortly thereafter, DG neuron activity also terminated. The gastric mill rhythm resumed $11 \mathrm{sec}$ after the end of the MPN stimulation. MPN resting potentials were $-58 \mathrm{mV}(A)$ and $-62 \mathrm{mV}(B)$. The recordings in $A$ and $B$ are from different preparations.

\section{MPN effects in the STG}

Several STG neurons in the crab participate in both the pyloric and the gastric mill rhythms. These include the IC, VD, and medial gastric (MG) motor neurons plus interneuron 1 (Int1) (Weimann et al., 1991; Norris et al., 1994a; Weimann and Marder, 1994). Nusbaum and Marder (1989b) showed that MPN stimulation increased the pyloric-timed activity of the IC neuron when activity in the CoGs was suppressed. We found that when the CoGs remained connected to the STG, MPN stimulation increased the pyloric-timed activity of all four of these gastro-pyloric neurons, regardless of whether the gastric mill rhythm was in progress. The effects of MPN on these neurons consisted of an increase in the depolarized amplitude of their pyloric-timed membrane potential oscillations (Fig. 4) as well as an increase in the number of action potentials per burst fired by each neuron (Fig. 4;

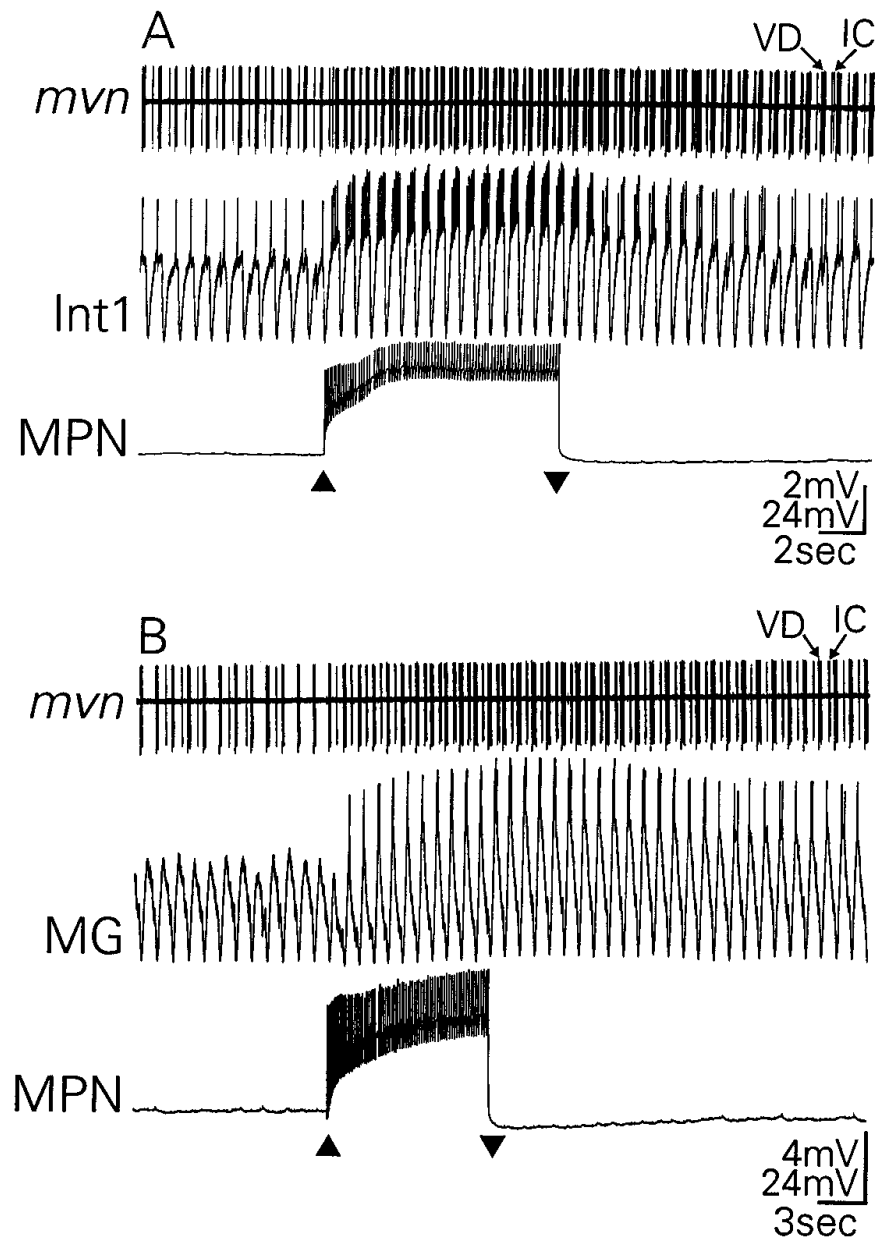

Figure 4. MPN increases the pyloric-timed activity of some STG gastropyloric neurons. $A$, During a time when there was an ongoing pyloric rhythm in the absence of a gastric mill rhythm, MPN stimulation (firing frequency, $13 \mathrm{~Hz}$ ) excited the pyloric rhythm ( $m v n)$ and increased the pyloric-timed activity of Int1, VD, and IC. This is evident from the increased number of action potentials fired per pyloric-timed burst in each of these neurons. MPN stimulation also caused an increase in the amplitude of the depolarized phase of the membrane potential oscillations of each neuron, as is evident here for Int1 and in $B$ for MG. These effects outlasted the stimulation and returned to baseline after $30 \mathrm{sec}$. $B$, MPN stimulation (firing frequency, $18 \mathrm{~Hz}$ ) evoked pyloric-timed impulse activity in MG. MG began to fire action potentials that were time-locked to the pyloric rhythm during the MPN stimulation. This activity level returned to baseline after $48 \mathrm{sec}$. MPN stimulation also increased the amplitude of the membrane potential oscillations of MG. Most hyperpolarized membrane potentials: $(A) \mathrm{Int} 1,-71 \mathrm{mV}$; MPN, $-51 \mathrm{mV}$; $(B) \mathrm{MG},-61 \mathrm{mV}$; MPN, $-49 \mathrm{mV}$.

Table 1). These effects tended to outlast the period of MPN stimulation by several tens of seconds.

In the absence of the gastric mill rhythm, the DG neuron is often silent in the isolated crab STNS. MPN stimulation had variable effects on DG neuron activity. DG activity was slightly enhanced ( $n=7 / 21$ preparations), inhibited ( $n=9 / 21)$, or not altered $(n=5 / 21)$. DG rarely exhibits pyloric-timed activity in vitro (Weimann et al., 1991), and MPN stimulation did not elicit either pyloric-timed activity ( $n=21$ preparations) or subthreshold oscillations in this neuron ( $n=8$ preparations). The variable effects of MPN on DG appear to be a consequence of MPN inhibition of other projection neurons that influence DG (see below). 


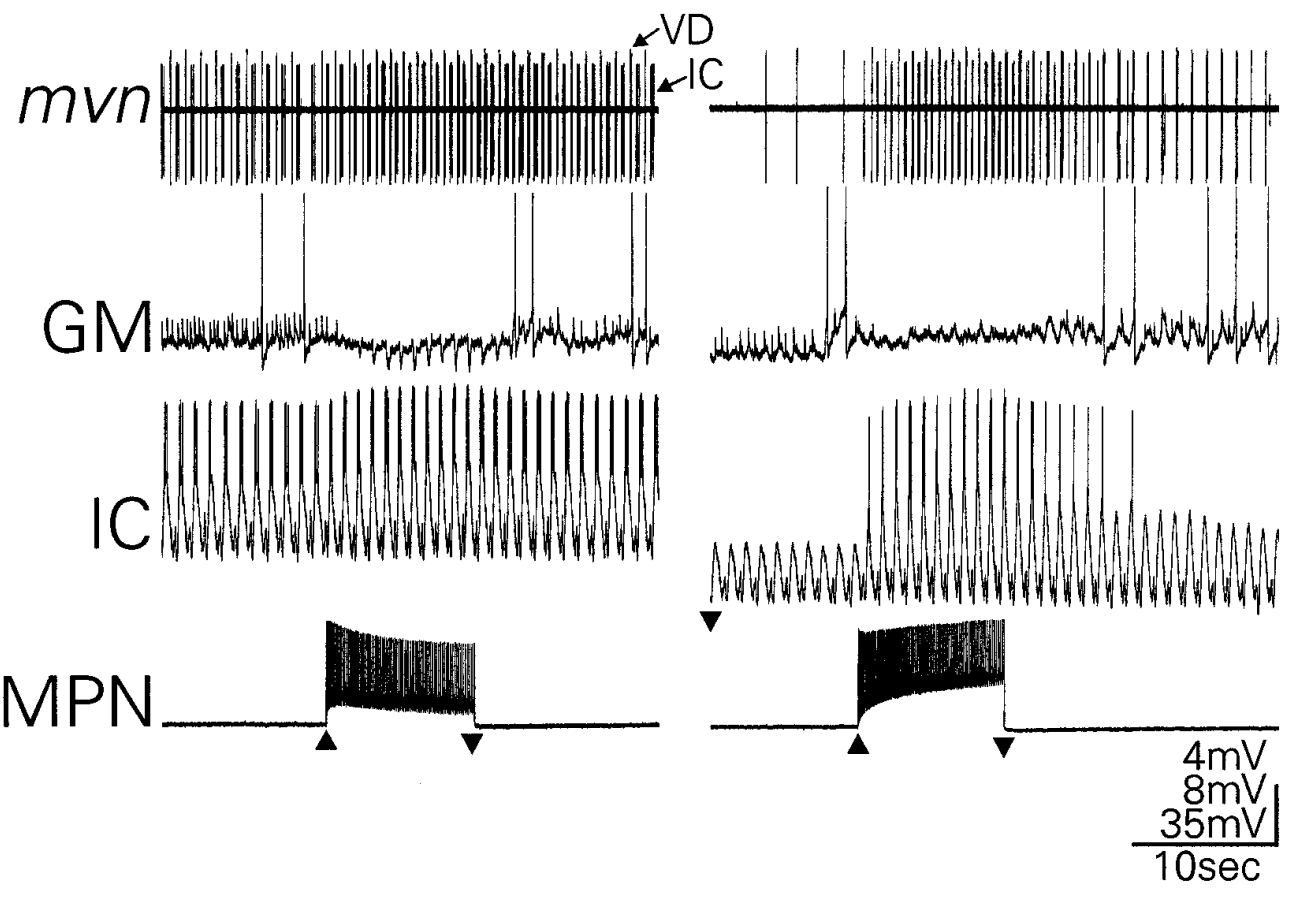

Figure 5. MPN excitation of the IC neuron elicits subthreshold pylorictimed inhibition in the GM neuron. Left, MPN stimulation (firing frequency, $10 \mathrm{~Hz}$ ) excited the IC and VD neurons and evoked pyloric-timed inhibition in GM. During MPN stimulation, there was also an elimination of the action potentials and tonically occurring EPSPs in GM. Right, When the IC membrane potential was hyperpolarized via DC current injection, MPN stimulation (firing frequency, $10 \mathrm{~Hz}$ ) still excited the pyloric rhythm, but it no longer evoked pyloric-timed inhibition in GM. However, the action potentials and tonic EPSPs in GM were still eliminated. Note that when IC was hyperpolarized, its response to MPN stimulation resulted in an activity level that was slightly weaker than that occurring before MPN stimulation in the absence of hyperpolarizing current injection. Most hyperpolarized membrane potentials: $(A) \mathrm{GM},-50 \mathrm{mV}$; IC, $-58 \mathrm{mV}$; MPN, $-70 \mathrm{mV} ;(B) \mathrm{GM}$, $-54 \mathrm{mV}$; IC, $-70 \mathrm{mV}$; MPN, $-70 \mathrm{mV}$.
Two additional gastric mill neurons, GM and LG, exhibit intermittent pyloric-timed slow wave oscillations and spikes. MPN stimulation increased the pyloric-timed inhibition to these neurons and did not enhance their activity. Instead, MPN stimulation decreased GM neuron activity ( $n=12 / 14$ preparations) (Fig. 5) and increased the pyloric-timed hyperpolarizations of its membrane potential ( $n=30 / 32$ preparations) (Fig. 5). Similarly, when LG was firing action potentials, MPN stimulation decreased LG activity ( $n=13 / 16$ preparations) and increased the amplitude of its pyloric-timed membrane potential hyperpolarizations $(n=$ 33/34 preparations) (see below).

It was possible that the MPN-elicited increases in the pylorictimed inhibition in these two gastro-pyloric neurons resulted from MPN excitation of other STG neurons. In six of six preparations in which GM was exhibiting pyloric-timed hyperpolarizations, MPN stimulation increased the amplitude of these hyperpolarizations. In 26 other preparations, GM did not exhibit these hyperpolarizations during saline superfusion. However, in 24 of these 26 preparations, MPN stimulation elicited pyloric-timed hyperpolarizations in GM. When IC neuron activity is strong, it provides inhibitory input to GM (Weimann, 1992), and IC activity is enhanced significantly by MPN stimulation (Nusbaum and Marder, 1989b; present study). We examined whether the MPN effects on GM occurred via MPN excitation of IC by stimulating MPN while reducing IC activity with hyperpolarizing current

Table 1. Effects of MPN stimulation on STG gastro-pyloric neurons

\# Spikes/pyloric rhythm-timed burst

\begin{tabular}{llll} 
& \multicolumn{2}{l}{ \# Spikes/pyloric rhythm-timed burst } \\
\cline { 2 - 4 } Neuron & Control & MPN stimulation & $n$ \\
\hline IC & $1.1 \pm 0.9$ & $3.3 \pm 1.2^{* *}$ & 23 \\
VD & $1.5 \pm 1.4$ & $2.4 \pm 1.5^{* *}$ & 21 \\
Int1 & $3.5 \pm 3.1$ & $5.7 \pm 3.2^{* *}$ & 11 \\
MG & $0.6 \pm 0.7$ & $2.3 \pm 2.1^{* *}$ & 11 \\
\hline
\end{tabular}

${ }^{* *} p \leq 0.01$ (paired Student's $t$ test)

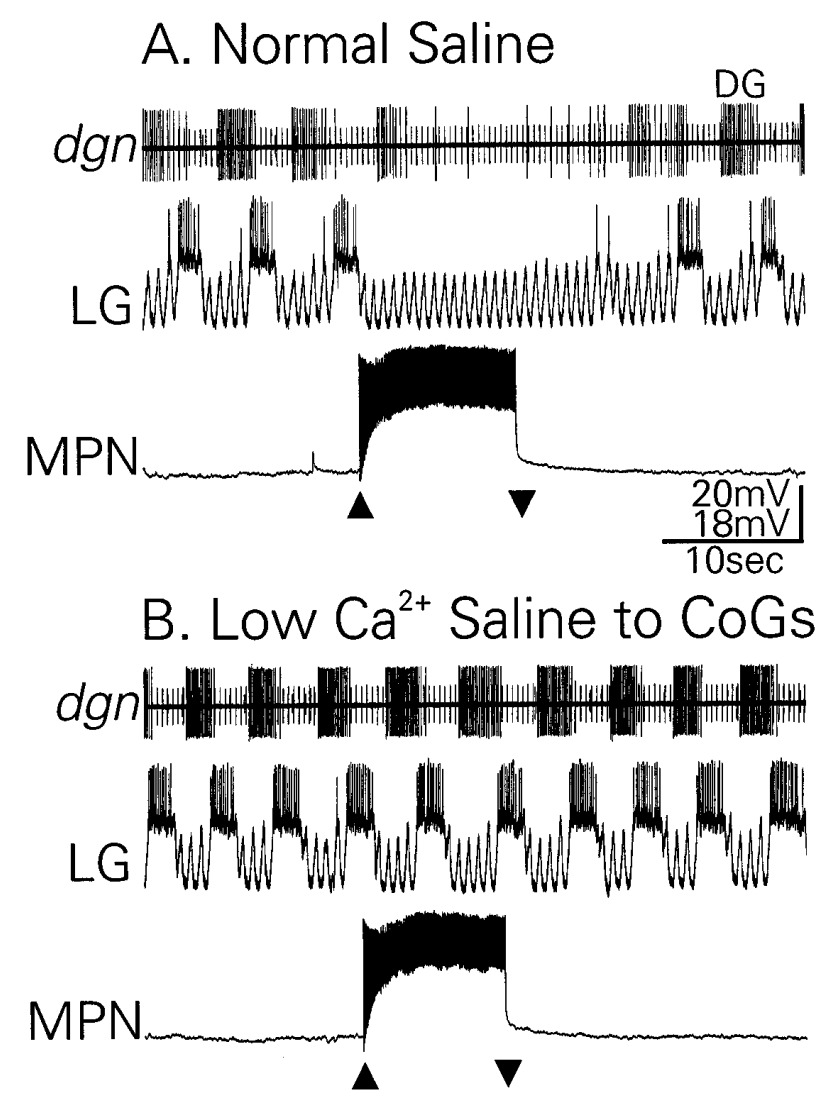

Figure 6. MPN does not inhibit the gastric mill rhythm when transmitter release is suppressed in the CoGs. $A$, When the CoGs were superfused with normal saline, MPN stimulation (firing frequency, $17 \mathrm{~Hz}$ ) inhibited the gastric mill rhythm, as evident by the elimination of LG and DG bursting. $B$, When transmitter release was suppressed in the CoGs by superfusion with low $\mathrm{Ca}^{2+}$ saline, MPN stimulation (firing frequency, 17 $\mathrm{Hz}$ ) had no effect on the gastric mill rhythm. Most hyperpolarized membrane potentials: $\mathrm{LG},-72 \mathrm{mV}$; MPN, $-50 \mathrm{mV}$. Calibration applies to both $A$ and $B$. 
Figure 7. MPN activity inhibits MCN1 and CPN2 in the CoGs. A, Left, Intracellular recordings of $\mathrm{LG}$ in the STG, MCN1 in the CoG and MPN in the esophageal nerve, posterior to the OG. LG is not firing action potentials but is receiving EPSPs from MCN1 and CPN2. The large-amplitude EPSPs represent input to LG from MCN1, and they are time-locked to the MCN1 action potentials. MCN1 is spontaneously active. LG is also receiving smaller amplitude EPSPs from CPN2 (see $B$ ). MPN stimulation (firing frequency, $11 \mathrm{~Hz}$ ) inhibited MCN1, causing a cessation of MCN1 activity and hyperpolarization of its membrane potential. This eliminated all of the EPSPs in LG. Note also that the MPN stimulation excited the pyloric rhythm $(m v n)$. Right, Schematic diagram indicating MPN inhibition of MCN1, removing excitatory input to LG. Dark cell bodies represent active neurons; light cell bodies indicate inactive neurons. Small, solid circles indicate transmitter-mediated synaptic inhibition; $T$-bars indicate an excitatory synapse. B, Left, Intracellular recordings of GM in the STG, CPN2 in the CoG and MPN in the esophageal nerve. GM is not firing action potentials but is receiving EPSPs from both CPN2 neurons, which are spontaneously active. MPN stimulation (firing frequency, $17 \mathrm{~Hz}$ ) inhibited both the recorded $\mathrm{CPN} 2$ and its contralateral homolog, as is evident by the (1) cessation of CPN2 activity, (2) associated hyperpolarization of the CPN2 membrane potential, and (3) elimination of the EPSPs that GM was receiving. The MPN stimulation also excited the pyloric rhythm (mvn). Right, Schematic diagram indicating that MPN inhibits CPN2, removing excitatory input to GM and LG (symbols as in $A$ ). Most hyperpolarized membrane potentials: (A) LG, $-44 \mathrm{mV}$; MCN1, $-66 \mathrm{mV}$; MPN, $-56 \mathrm{mV} ;(B) \mathrm{GM},-64 \mathrm{mV}$; CPN2, $-56 \mathrm{mV}$; MPN, $-65 \mathrm{mV}$.
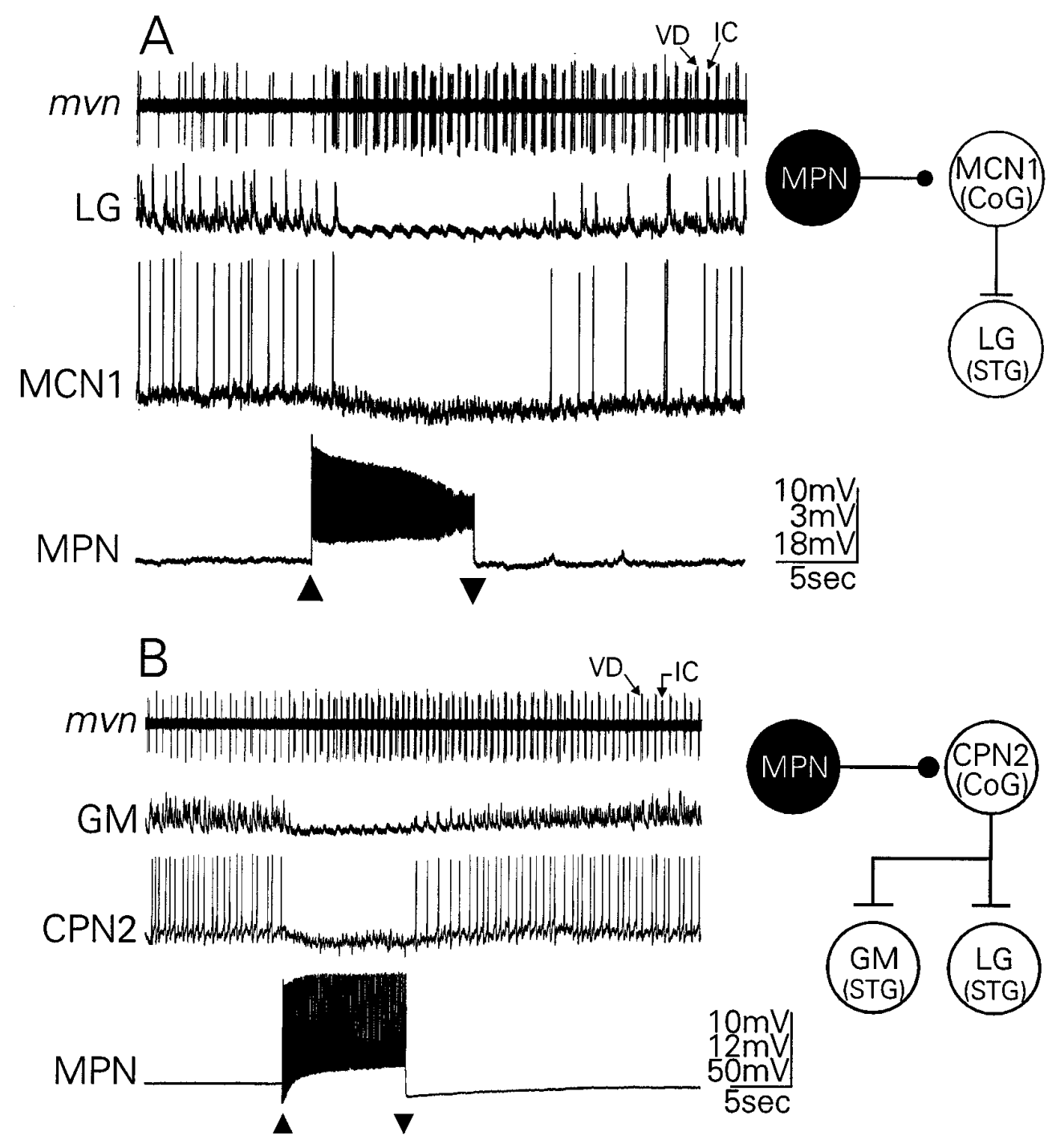

injection (Fig. 5). With IC activity reduced, MPN stimulation did not elicit these pyloric-timed events in $\operatorname{GM}(n=11$ preparations).

The LG neuron receives pyloric-timed inhibitory input from two sources, Int1 (Norris et al., 1994a) and the pyloric pacemaker ensemble (D. Blitz, M. Nusbaum, unpublished observations). The increased activity of these neurons during MPN stimulation (Int1, Fig. 4, Table 1; pyloric pacemaker ensemble, Nusbaum and Marder, 1989a) is responsible for the pyloric-timed hyperpolarizations in the LG membrane potential (data not shown).

In addition to the pyloric-timed effects of MPN on GM and LG, MPN stimulation consistently eliminated spontaneously occurring EPSPs in GM (Fig. 5; $n=32$ preparations) and LG (see below) ( $n=37$ preparations) that were not related to the pyloric rhythm. These EPSPs result entirely from spontaneous activity in the projection neurons MCN1 and CPN2 (Coleman and Nusbaum, 1994; Norris et al., 1994a). Our data therefore suggested that MPN activation eliminated the EPSPs in LG and GM and inhibited the gastric mill rhythm by inhibiting MCN1 and CPN2.

\section{MPN effects in the CoGs}

If MPN did indeed inhibit MCN1 and CPN2 and thereby inhibit the gastric mill rhythm, then it might have done so within the CoGs, at their terminals within the STG, or at both locations. We first examined whether the inhibitory effects of MPN occurred in the CoGs. To this end, we selectively superfused the CoGs and OG with low $\mathrm{Ca}^{2+}$ saline (see Materials and Methods) to suppress transmitter release. This saline often initiated or increased spontaneous activity in CoG neurons and elicited a gastric mill rhythm from the STG. The increased activity in CoG neurons may result from an elimination of the inhibitory synaptic effects of spontaneously active neurons in the CoGs.

As in our previous experiments, before we suppressed transmitter release in the CoGs, MPN stimulation inhibited the gastric mill rhythm (Fig. 6A). In contrast, when transmitter release in the CoGs was suppressed, MPN stimulation no longer inhibited the gastric mill rhythm (Fig. $6 B ; n=5$ preparations). Nonetheless, 


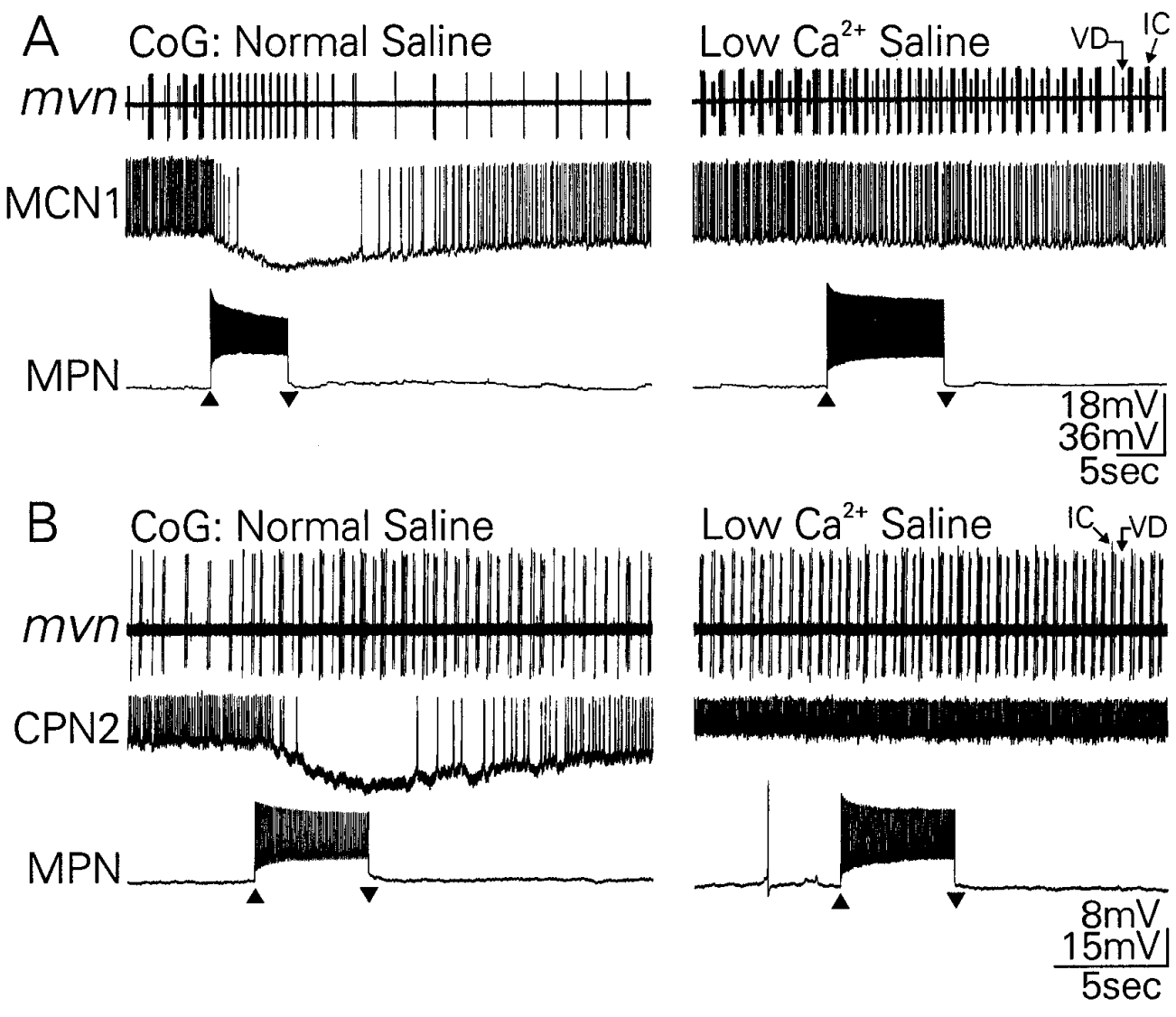

Figure 8. MPN activity does not inhibit MCN1 or CPN2 when transmitter release in the CoGs is suppressed. $A$, Left, MPN stimulation (firing frequency, $14 \mathrm{~Hz}$ ) inhibited MCN1, thereby terminating MCN1 activity and causing a hyperpolarization of the MCN1 membrane potential. Note that MPN stimulation excited the pyloric rhythm (mvn). Right, When the CoGs were selectively superfused with low $\mathrm{Ca}^{2+}$ saline to suppress transmitter release, MPN stimulation had no effect on MCN1. During this time, the STG was superfused with normal saline, and consequently MPN stimulation still excited the pyloric rhythm. $B$, Left, MPN stimulation (firing frequency, $19 \mathrm{~Hz}$ ) inhibited CPN2, causing CPN2 to hyperpolarize and stop firing action potentials. Right, With transmitter release suppressed in the CoGs, MPN stimulation had no effect on CPN2. Most hyperpolarized membrane potentials: $(A) \mathrm{MCN} 1,-65 \mathrm{mV}$; MPN, $-75 \mathrm{mV}$; $(B) \mathrm{CPN} 2,-63 \mathrm{mV}$; MPN, $-56 \mathrm{mV}$. The recordings in $A$ and $B$ are from different preparations.

under the latter condition, MPN still effectively excited the pyloric rhythm in the STG, which was continually superfused with normal saline (see below).

It was possible that MPN was inhibiting MCN1 and CPN2 in the CoGs and thereby removing excitation to the gastric mill system. Alternatively, MPN might have been exciting a $\mathrm{CoG}$ neuron(s) that projected to the STG and inhibited the gastric mill rhythm. If MPN was indeed inhibiting the gastric mill rhythm not by inhibiting MCN1 and CPN2 in the CoG, but by exciting a $\mathrm{CoG}$ neuron that projected to the STG, then MPN should be able to suppress this rhythm regardless of where MCN1 was activated. To test this latter possibility, we examined whether MPN stimulation could inhibit the gastric mill rhythm when this rhythm was elicited by activating MCN1 at a site outside of the CoG. This would circumvent any possible inhibitory influence in the CoG of MPN on MCN1 activity. Thus, we elicited the gastric mill rhythm by selectively activating MCN1 via extracellular stimulation of the ion (Coleman et al., 1995). We found that MPN stimulation did not inhibit gastric mill rhythms elicited by ion stimulation $(n=6$ preparations). Consequently, we focused on determining whether the MPN inhibition of the gastric mill rhythm resulted from its having inhibitory actions on MCN1 and CPN2 in the CoGs.

MPN stimulation did indeed inhibit both MCN1 and CPN2 in the CoGs (Fig. 7). Activity in both of these projection neurons was either reduced or terminated by MPN stimulation ( $n=42$ preparations). Accompanying this inhibition, these neurons exhibited a slow hyperpolarization that often outlasted the MPN stimulation by several seconds. Discrete IPSPs time-locked to each MPN action potential were not evident in either MCN1 or CPN2. MPN inhibition of these neurons, however, was often accompanied by a barrage of depolarizing postsynaptic potentials that were not time-locked to the MPN action potentials.

Note that at the same time that MPN activity inhibited MCN1 and CPN2 in the CoG, it was exciting the pyloric rhythm in the STG (Figs. $7 A, B$ ). Concurrently, the MCN1-elicited EPSPs in LG were eliminated (Fig. $7 A$ ). MCN1 action potentials elicit relatively large-amplitude monosynaptic electrical EPSPs in LG (Fig. 7 $A$ ) (Coleman et al., 1995). CPN2 action potentials elicit smaller amplitude, fixed-latency EPSPs in LG as well as in GM (Norris et al., 1994a). In the isolated STNS of C. borealis, all spontaneously occurring EPSPs in GM originate from CPN2 activity (Norris et al., 1994a; D. Blitz and M. Nusbaum, unpublished observations). Regardless of whether MCN1 was spontaneously active, LG and GM often received a tonic barrage of EPSPs from CPN2, and these EPSPs were consistently eliminated coincident with the MPN-mediated inhibition of CPN2 activity (Fig. 7B).

To confirm that the low $\mathrm{Ca}^{2+}$ saline superfusion of the CoGs and OG that we used to suppress MPN inhibition of the gastric mill rhythm was also sufficient to suppress its inhibition of MCN1 and CPN2, we again selectively superfused these ganglia with low $\mathrm{Ca}^{2+}$ saline. Under this condition, MPN stimulation no longer influenced either MCN1 (Fig. $8 A ; n=7$ preparations) or CPN2 (Fig. $8 B ; n=9$ preparations). In addition, MPN neither reduced nor eliminated the EPSPs in LG and GM, nor did it influence any other effects of MCN1 and CPN2 within the STG. Note that during these times, MPN stimulation continued to excite the pyloric rhythm in the STG (Fig. 8). These results support the hypothesis that the MPN-mediated inhibition of these projection neurons in the CoG is responsible for the MPN-mediated inhibition of the gastric mill rhythm in the STG. It also suggested that 


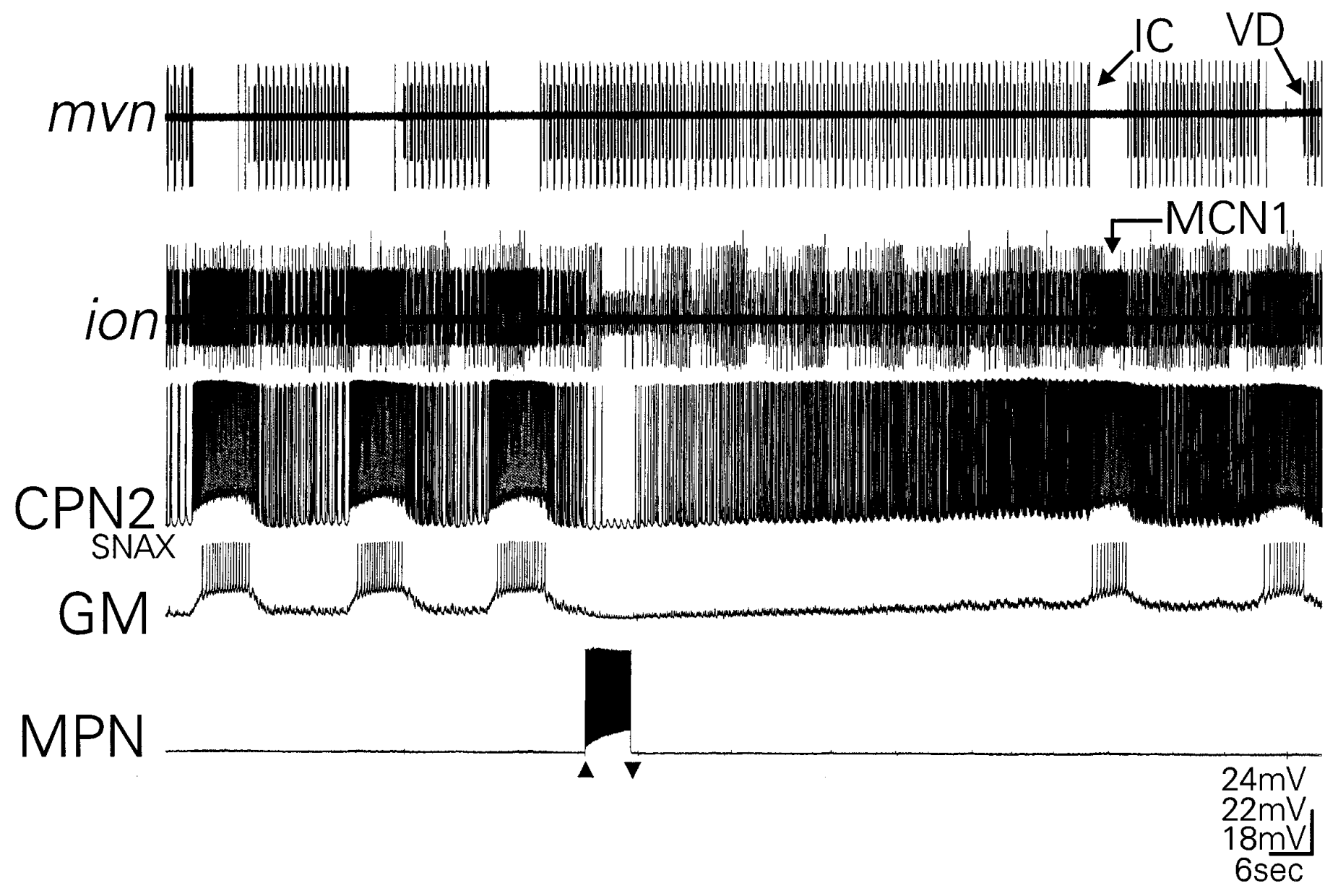

Figure 9. During an ongoing MCN1/CPN2-elicited gastric mill rhythm, MPN stimulation inhibits MCN1, CPN2, and the gastric mill rhythm. The gastric mill rhythm is represented here by the rhythmic inhibition of IC and VD $(m v n)$ and the rhythmic bursting of the GM neuron. MCN1 and CPN2 are both firing high-frequency bursts of action potentials, and both are participating in the production of this gastric mill rhythm. CPN2 activity is monitored by an intra-axonal recording of its stomatogastric nerve axon (SNAX). MPN stimulation (firing frequency, $16 \mathrm{~Hz}$ ) inhibited MCN1, CPN2, and the gastric mill rhythm. After MPN stimulation, MCN1 and CPN2 activity levels gradually returned to prestimulus levels, at which time the gastric mill rhythm resumed. This occurred $\sim 1 \mathrm{~min}$ after the end of the MPN stimulation. Most hyperpolarized membrane potentials: $\mathrm{CPN} 2_{\mathrm{SNAX}},-66 \mathrm{mV}$; GM, $-52 \mathrm{mV}$; MPN, $-82 \mathrm{mV}$.

there was no functionally important influence of MPN on the STG terminals of these projection neurons. The effect of low $\mathrm{Ca}^{2+}$ saline was readily reversible.

We also examined the influence of MPN on MCN1 and CPN2 during gastric mill rhythms to document that MPN did indeed inhibit these projection neurons during times when it inhibited the gastric mill rhythm. In all preparations studied, we found that MPN stimulation inhibited both MCN1-elicited $(n=7)$ and MCN1/CPN2-elicited $(n=7)$ gastric mill rhythms coincident with its inhibition of these projection neurons (Fig. 9). Furthermore, the resumption of these gastric mill rhythms after MPN stimulation coincided with the return of MCN1 and CPN2 activity to prestimulus levels. Note, in Figure 9, that MPN stimulation terminated activity in both MCN1 and CPN2 for the duration of MPN activity $(6 \mathrm{sec})$. It then took $\sim 1$ min longer before the activity level of these projection neurons was again sufficiently strong to drive the gastric mill rhythm.

Also noteworthy in Figure 9 is that there was no indication of MPN-mediated synaptic inhibition in the CPN2 ${ }_{\text {SNAX }}$ recording. The stomatogastric nerve axon (SNAX) recording is an intraaxonal recording of CPN2 at the entrance to the STG. Synaptic events occurring at the STG terminals of projection neurons are readily recorded at this site (Nusbaum et al., 1992; Coleman and Nusbaum, 1994). In contrast, the SNAX recording site is electrotonically remote from the CoG (Coleman and Nusbaum, 1994). When MPN stimulation eliminated the CPN2 action potentials, which had been propagating toward the STG from the $\mathrm{CoG}$, the only synaptic events evident in $\mathrm{CPN} 2_{\text {SNAx }}$ were pyloric-timed membrane potential oscillations (Fig. 9). These oscillations result from pyloric-timed synaptic input to CPN2 in the STG (D. Blitz and M. Nusbaum, unpublished observations).

\section{DISCUSSION}

\section{Motor pattern selection}

Our results indicate that the modulatory projection neuron MPN elicits a specific motor pattern from the STG network via both direct and indirect effects. Its excitatory actions in the STG enable MPN to elicit a pyloric rhythm that is comparable to the rhythm elicited by proctolin superfusion (Nusbaum and Marder, 1989b). We showed here that these MPN actions also include enhancing the pyloric-timed activity of some gastric mill neurons in the STG. At the same time, via its inhibitory effects on projection neurons in the CoGs, MPN inhibits the expression of the gastric mill rhythm in the STG (Fig. 10). These inhibitory actions include the 


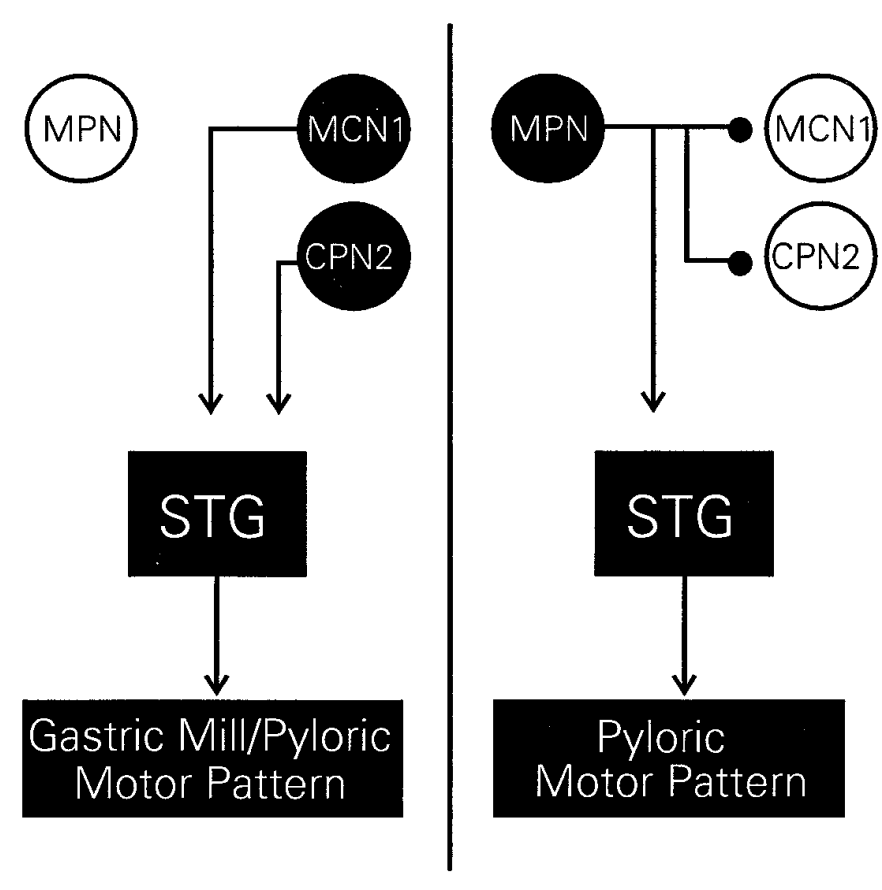

Figure 10. Schematic indicating the motor patterns elicited from the STG network as a result of activity in MCN1/CPN2 or MPN. Left, When MCN1 and CPN2 are active, specific versions of the pyloric rhythm (Bartos and Nusbaum, 1997) and gastric mill rhythm (Coleman and Nusbaum, 1994; Norris et al., 1994a) are elicited. Right, When MPN is active, it excites the pyloric rhythm in the STG (Nusbaum and Marder, 1989a,b; present study) and inhibits MCN1 and CPN2, removing their excitation to the gastric mill system and eliminating the gastric mill rhythm (present study). This results in a distinct pyloric rhythm in the absence of the gastric mill rhythm. Dark cell bodies represent active neurons; light cell bodies represent inactive neurons.

MPN-mediated inhibition of MCN1 and CPN2, two projection neurons identified previously, the activity of which is instrumental in the production of gastric mill rhythms (Coleman and Nusbaum, 1994; Norris et al., 1994a; Coleman et al., 1995). At least two other CoG projection neurons, MCN5 and MCN7, elicit different versions of the gastric mill rhythm (Coleman et al., 1993; Norris et al., 1994b; D. Blitz, M. Coleman, B. Norris, and M. Nusbaum, unpublished observations). The MPN influence on these other projection neurons, and the gastric mill rhythms they elicit, remains to be determined.

Although proctolin superfusion to the STG mimics the effects of MPN on the pyloric rhythm, proctolin application does not mimic the effects of MPN stimulation on gastric mill rhythms. In fact, whereas MPN stimulation inhibits the gastric mill rhythm, application of proctolin to the CoGs excites MCN1 and CPN2 and thereby elicits the gastric mill rhythm (Blitz and Nusbaum, 1995). In addition to being proctolin-immunoreactive, MPN also exhibits GABA-like immunoreactivity (Nusbaum et al., 1989). Although MPN elicits a proctolin-like pyloric motor pattern in the STG, it appears to use either GABA or a third, unidentified transmitter in the CoGs to inhibit the gastric mill rhythm.

The MPN-elicited increase in pyloric-timed activity of at least some gastric mill neurons is likely to be functionally effective. For example, in the intact crab Cancer pagurus, Heinzel et al. (1993) showed that the pyloric-timed activity of the MG neuron elicited pyloric-timed pumping movements of the lateral teeth. Although MPN often elicited action potentials in MG, this MG activity was usually less intense than that occur- ring during gastric mill rhythms. However, in C. pagurus, even two to three action potentials per burst in MG elicits pumping movements of the lateral teeth (Heinzel et al., 1993). It is also possible that the depolarized component of the pyloric-timed oscillations in gastric mill neurons that occurs in response to MPN stimulation is sufficient to elicit postsynaptic effects. STG neurons use action potentials to transmit signals to their distant targets, but within the STG, they communicate primarily via graded release of neurotransmitter (Raper, 1979; Graubard et al., 1983).

In addition to the MPN effects in the STG, some of the MPN effects on STG neurons are likely to result from its inhibition of MCN1 and CPN2. For example, MCN1 excites DG (Nusbaum et al., 1992; Coleman and Nusbaum, 1994) and CPN2 inhibits DG (Norris et al., 1994a), whereas MPN has no direct effect on DG. Thus, the DG response to MPN stimulation during times when a gastric mill rhythm is not in progress depends partly on the level of spontaneous activity in MCN1 and CPN2.

In the STNS of several different species, it has been shown that distinct motor patterns can be elicited from the STG network by stimulation of different projection neurons (Nagy and Dickinson, 1983; Dickinson et al., 1988; Katz and Harris-Warrick, 1990; Coleman et al., 1993; Coleman and Nusbaum, 1994; Norris et al., 1994a,b, 1996). Unlike the MPN-elicited motor pattern, these selected motor patterns appear to result entirely from the effects of each projection neuron within the STG. Additionally, in the lobster Homarus gammarus, activation of the pyloric suppressor (PS) neuron eliminates the pyloric and gastric mill rhythms (Meyrand et al., 1994). PS neuron activity assembles a different functional circuit that incorporates elements of several STNS networks, including some neurons from the gastric mill and pyloric circuits. Again, the incorporation of some STG neurons into this different circuit appears to result from the actions of PS within the STG. However, recent work has demonstrated that after PS activity has ceased, there is a long-lasting activation of the gastric mill rhythm that results in part from PS activation of another projection neuron (Faumont et al., 1996).

In other systems, activation of neurons from other regions of the CNS also elicits distinct motor patterns from a common network. For example, stimulation of a single neuron in the crab brain can cause a switch from the forward to the reverse form of the ventilation motor pattern (DiCaprio, 1990). Similarly, stimulation of different neurons in the cerebral ganglion of Aplysia can elicit different feeding-related motor patterns (Rosen et al., 1991). These motor patterns appear to result from activation of overlapping subsets of neurons. However, the extent to which distinct projection neurons interact, separate from their direct influences on a common network, has not been elucidated in most systems. One system in which there is some information is the leech swimming system. Leechswimming can be elicited by activation of a swim trigger neuron that directly influences swim gating and network neurons and also inhibits a projection neuron, the activity of which inhibits the swim motor pattern (Brodfuehrer and Burns, 1995).

In this paper, we have shown that an identified modulatory projection neuron selects a specific motor output from a multifunctional network by direct modulation of pyloric circuit neurons to excite the pyloric motor pattern and via inhibition of projection neurons, the activity of which would evoke the functionally related but distinct gastric mill motor pattern (Fig. 10). We do not yet know, at the behavioral level, why MPN inhibits the gastric mill rhythm. One possibility, however, is that MPN does not suppress 
all forms of the gastric mill rhythm. Perhaps in the intact crab, MPN is normally coactivated with one or more other projection neurons that elicit a distinct version of the gastric mill rhythm.

In addition to ensuring selection of particular motor patterns from a multifunctional network, interactions among parallel pathways might also be used effectively to increase the variety of motor patterns produced by the targeted network. Such interactions might allow different combinations of projection neurons to be coactivated, thereby evoking distinct outputs from the affected network. The behaviorally relevant pathways by which some projection neurons are activated in the stomatogastric system have been identified (Nagy and Moulins, 1987; Simmers and Moulins, 1988; Blitz and Nusbaum, 1996). For most, however, these pathways remain to be determined.

\section{REFERENCES}

Bartos M, Nusbaum MP (1997) Intercircuit control of motor pattern modulation by presynaptic inhibition. J Neurosci 17:2247-2256.

Blitz DM, Nusbaum MP (1994) Motor pattern selection by a modulatory projection neuron. Soc Neurosci Abstr 20:23.

Blitz DM, Nusbaum MP (1995) Neuropeptide activation of rhythmic motor activity via excitation of identified projection neurons. Soc Neurosci Abstr 21:629.

Blitz DM, Nusbaum MP (1996) Sensory neuron activation of modulatory projection neurons. Soc Neurosci Abstr 22:1375.

Blitz DM, Christie AE, Marder E, Nusbaum MP (1995) Distribution and effects of two families of tachykinin-like peptides in the stomatogastric nervous system of the crab, Cancer borealis. J Comp Neurol 354:282-294.

Brodfuehrer PD, Burns A (1995) Neuronal factors influencing the decision to swim in the medicinal leech. Neurobiol Learn Memory 63:192-199.

Brodfuehrer PD, Friesen WO (1986) Initiation of swimming activity by trigger neurons in the leech subesophageal ganglion. I. Output connections of Tr1 and Tr2. J Comp Physiol [A] 159:489-502.

Coleman MJ (1995) Dynamic modulation of a rhythmically active neural network in the stomatogastric nervous system of the crab, Cancer borealis. PhD thesis, University of Alabama at Birmingham.

Coleman MJ, Nusbaum MP (1994) Functional consequences of compartmentalization of synaptic input. J Neurosci 14:6544-6552.

Coleman MJ, Norris BJ, Nusbaum MP (1993) Functional modification of rhythmic motor activity by a modulatory projection neuron. Soc Neurosci Abstr 19:1701.

Coleman MJ, Meyrand P, Nusbaum MP (1995) A switch between two modes of synaptic transmission mediated by presynaptic inhibition. Nature 378:502-505.

DiCaprio RA (1990) An interneurone mediating motor programme switching in the ventilatory system of the crab. J Exp Biol 154:517-535.

Dickinson PS (1995) Interactions among neural networks for behavior. Curr Opin Neurobiol 5:792-798.

Dickinson PS, Nagy F, Moulins M (1988) Control of central pattern generators by an identified neurone in crustacea: activation of the gastric mill motor pattern by a neurone known to modulate the pyloric network. J Exp Biol 136:53-87.

Faumont S, Simmers J, Meyrand P (1996) Stabilizing control of a motor pattern generating network via interacting higher order modulatory interneurons. Soc Neurosci Abstr 22:132.

Graubard K, Raper JA, Hartline DK (1983) Graded synaptic transmission between identified spiking neurons. J Neurophysiol 50:508-521.

Grillner S, Deliagina T, Ekeberg Ö, El Manira A, Hill RA, Lansner A, Orlovsky GN, Wallén P (1995) Neural networks that co-ordinate locomotion and body orientation in lamprey. Trends Neurosci 18:270-279.

Harris-Warrick RM, Marder E (1991) Modulation of neural networks for behavior. Annu Rev Neurosci 14:39-57.

Harris-Warrick RM, Marder E, Selverston A, Moulins M (1992a) Dynamic biological networks: the stomatogastric nervous system. Cambridge, MA: MIT.

Harris-Warrick RM, Nagy F, Nusbaum MP (1992b) Neuromodulation of stomatogastric networks by identified neurons and transmitters. In: Dynamic biological networks: the stomatogastric nervous system
(Harris-Warrick RM, Marder E, Selverston AI, Moulins M, eds), pp 87-137, Cambridge, MA: MIT.

Heinzel H, Weimann JM, Marder E (1993) The behavioral repertoire of the gastric mill of the crab, Cancer pagurus: an in situ endoscopic and electrophysiological examination. J Neurosci 13:1793-1803.

Johnson BR, Hooper SL (1992) Overview of the stomatogastric nervous system. In: Dynamic biological networks: the stomatogastric nervous system (Harris-Warrick RM, Marder E, Selverston AI, Moulins M, eds), pp 1-30, Cambridge, MA: MIT.

Katz PS (1995) Intrinsic and extrinsic neuromodulation of motor circuits. Curr Opin Neurobiol 5:799-808.

Katz PS, Harris-Warrick RM (1990) Neuromodulation of the crab pyloric central pattern generator by serotonergic/cholinergic proprioceptive afferents. J Neurosci 10:1495-1512.

Katz PS, Harris-Warrick RM (1991) Recruitment of crab gastric mill neurons into the pyloric motor pattern by mechanosensory afferent stimulation. J Neurophysiol 65:1442-1451.

Kiehn O, Kjærulff O (1996) Spatiotemporal characteristics of 5-HT and dopamine-induced rhythmic hindlimb activity in the in vitro neonatal rat. J Neurophysiol 75:1472-1482.

Marder E, Calabrese RL (1996) Principles of rhythmic motor pattern generation. Physiol Rev 76:687-717.

Marder E, Weimann JM (1992) Modulatory control of multiple task processing in the stomatogastric nervous system. In: Neurobiology of motor programme selection (Kien J, McCrohan C, Winlow B, eds), pp 3-19. New York: Pergamon.

Marder E, Christie AE, Kilman VL (1995) Functional organization of cotransmission systems: lessons from small nervous systems. Invert Neurosci 1:105-112.

Meyrand P, Simmers J, Moulins M (1994) Dynamic construction of a neural network from multiple pattern generators in the lobster stomatogastric nervous system. J Neurosci 14:630-644.

Nagy F, Dickinson PS (1983) Control of a central pattern generator by an identified modulatory interneurone in crustacea. I. Modulation of the pyloric motor output. J Exp Biol 105:33-58.

Nagy F, Moulins M (1987) Extrinsic inputs. In: The crustacean stomatogastric system (Selverston AI, Moulins M, eds), pp 205-242. Berlin: Springer.

Norris BJ, Coleman MJ, Nusbaum MP (1994a) Recruitment of a projection neuron determines gastric mill motor pattern selection in the stomatogastric nervous system of the crab, Cancer borealis. J Neurophysiol 72:1451-1463.

Norris BJ, Coleman MJ, Nusbaum MP (1994b) Distinct responses of electrically-coupled pacemaker neurons to activation of a modulatory projection neuron. Soc Neurosci Abstr 20:23.

Norris BJ, Coleman MJ, Nusbaum MP (1996) Pyloric motor pattern modification by a newly identified projection neuron in the crab stomatogastric nervous system. J Neurophysiol 75:97-108.

Nusbaum MP, Kristan Jr WB (1986) Swim initiation in the leech by serotonin-containing interneurons, cells 21 and 61. J Exp Biol 122:277-302.

Nusbaum MP, Marder E (1989a) A modulatory proctolin-containing neuron (MPN). I. Identification and characterization. J Neurosci 9:1591-1599.

Nusbaum MP, Marder E (1989b) A modulatory proctolin-containing neuron (MPN). II. State-dependent modulation of rhythmic motor activity. J Neurosci 9:1600-1607.

Nusbaum MP, Cournil I, Golowasch J, Marder E (1989) Modulating rhythmic motor activity with a proctolin- and GABA-containing neuron. Soc Neurosci Abstr 15:366.

Nusbaum MP, Weimann JM, Golowasch J, Marder E (1992) Presynaptic control of modulatory fibers by their neural network targets. J Neurosci 12:2706-2714.

Powers LW (1973) Gastric mill rhythms in intact crabs. Comp Biochem Physiol 46A:767-783.

Raper JA (1979) Nonimpulse-mediated synaptic transmission during the generation of a cyclic motor program. Science 205:304-306.

Rosen SC, Teyke T, Miller MW, Weiss KR, Kupfermann I (1991) Identification and characterization of cerebral-to-buccal interneurons implicated in the control of motor programs associated with feeding in Aplysia. J Neurosci 11:3630-3655.

Rossignol S, Dubuc R (1994) Spinal pattern generation. Curr Opin Neurobiol 4:894-902.

Selverston AI, Moulins M (1987) The crustacean stomatogastric system. Berlin: Springer. 
Simmers J, Moulins M (1988) A disynaptic sensorimotor pathway in the lobster stomatogastric system. J Neurophysiol 59:740-756.

Skiebe P, Schneider H (1994) Allatostatin peptides in the crab stomatogastric nervous system: inhibition of the pyloric motor pattern and distribution of allatostatin-like immunoreactivity. J Exp Biol 194:195-208.

Soffe SR (1993) Two distinct rhythmic motor patterns are driven by common premotor and motor neurons in a simple vertebrate spinal cord. J Neurosci 13:4456-4469.

Thorogood MS, Brodfuehrer PD (1995) The role of glutamate in swim initiation in the medicinal leech. Invert Neurosci 1:223-233.

Weeks JC, Kristan Jr WB (1978) Initiation, maintenance and modulation of swimming in the medicinal leech by the activation of a single neurone. J Exp Biol 77:71-88.
Weimann JM (1992) Multiple task processing in neural networks: numerous central pattern generators in the stomatogastric nervous system of the crab, Cancer borealis. $\mathrm{PhD}$ thesis, Brandeis University.

Weimann JM, Marder E (1994) Switching neurons are integral members of multiple oscillatory networks. Curr Biol 4:896-902.

Weimann JM, Meyrand P, Marder E (1991) Neurons that form multiple pattern generators: identification and multiple activity patterns of gastric/pyloric neurons in the crab stomatogastric system. J Neurophysiol 65:111-112.

Weimann JM, Marder E, Evans B, Calabrese RL (1993) The effects of SDRNFLRFamide and TNRNFLRFamide on the motor patterns of the stomatogastric ganglion of the crab, Cancer borealis. J Exp Biol 181:1-26. 